\title{
The effect of cyclic cryogenic exposure on the dispersion parameters of humic substances
}

Orlov A.S., Kuznetsova I.A., Mironenko K.A., Ponomareva T.I., Zubov I.N.

N. Laverov Federal Center for Integrated Arctic Research Russian Academy of Science, Arkhangelsk, Russia, alseror@yandex.ru

doi: 10.36291/HIT.2019.orlov.042

Humic substances are one of the main structure-forming components of soils. These are responsible for its fertility and resistance to erosion processes, which can occur under the influence of both natural and anthropogenic factors. Such factors in the cold climate of the European North of the Russian Federation include, first of all, the cyclic cryogenic exposure. Its influence on the state of the humus component of soils is currently scarcely investigated. It is known that one of the forms of the presence of humic acids in the soils is the colloidal (semi-colloidal) form [1-3]. At the same time, it should be noted the extremely low stability and regenerative capacity of soils of the Arctic regions.

The goal of this research is to investigate the effect of cyclic cryogenic exposure on colloid-dispersion parameters of the humic substances.

An analysis of the data obtained by the method of quantum correlation spectroscopy allows saying that a rather high polydispersity characterizes the studied sample of humates isolated from the coarse humus horizon of forest podzolic soil. It should be noted that even in the region of low concentrations $(100 \mathrm{mg} / \mathrm{I})$, supramolecular formations $\mathrm{D}=80-3000 \mathrm{~nm}$ are fixed in the solution of humic substances, which is apparently due to their functional nature and indicates a high ability to intermolecular interactions. In this case, the contribution of groups of particles of each dimension to the dynamic light scattering is directly proportional to both their numerical value and diameter.

The obtained results indicate that cyclic cryogenic exposure contributes to the gradual partial destruction of supramolecular formations of the humic substances. It is confirmed both by a decrease in the contribution to the light scattering of a group of large associates with $D=500-3000 \mathrm{~nm}$, whose contribution to the total number of particles is not significant, and the total redistribution of particles by size. It is seen that even with a fourtime freeze-thaw cycle, particles are redistributed in size from $D=80-500 \mathrm{~nm}$ to $D=20$ $100 \mathrm{~nm}$.

Thus, the results obtained during this study indicate the sensitivity of the hydrodynamic characteristics of humic substances to cyclic cryogenic exposure. It is shown that humates isolated from the coarse humus horizon of forest podzolic soil, even with significant dilutions, are predominantly in the form of supramolecular formations of an associative nature. It has been established that cyclic freezing contributes to a decrease in colloid-dispersion characteristics (particle sizes and contribution to light scattering) in aqueous solutions of humates. That is associated, apparently, with the partial destruction of their macromolecular formations and requires further investigation.

Acknowledgements. The reported study was funded by RFBR according to the research project № 18-05-60151 \& № 18-35-00552.

\section{References}

1. Orlov. D.S. // Moscow: MSU. 1990. p. 325 (In Russian).

2. Popov A.I. // Saint-Petersburg: St. Petersburg University Press. 2004. p. 248 (In Russian).

3. Tate R. // Moscow: Mir. 1991. p. 400 (In Russian). 